\title{
Nem santa, nem pecadora: novas roupagens, velhas dicotomias na coisificação da mulher
}

\author{
Neither saint nor sinner: new outlooks, \\ old dichotomies in the reification of women
}

Marilia de Oliveira de Sousa
Assistente social formada pela UFF — Rio das Ostras. Rio das Ostras, RJ, Brasil. o.sousamarilia@gmail.com

Paula Martins Sirelli

Professora do curso de Serviço Social da UFF — Rio das Ostras. Rio das Ostras, RJ, Brasil. paulasirelli@yahoo.com.br

Resumo: Analisamos o movimento histórico de dominação da mulher no capitalismo, entendendo que as relações sociais de sexo e gênero são responsáveis pelos altos índices de violência contra as mulheres, uma das múltiplas expressões da questão social. A coisificação do corpo feminino reforçado pela mídia é acompanhada pela ideia da liberdade sexual, uma forma de aproximação da mulher ao seu corpo e sexualidade, mas que tende a ser utilizada como reafirmação do corpo feminino como coisa a ser consumida.

Palavras-chave: Violência contra a mulher. Coisificação. Capitalismo. Serviço Social.
Abstract: We analyze the historical movement of female domination in capitalism, understanding that the social relations of sex and gender are responsible for the high rates of violence against women, one of the multiple expressions of the social question. The reification of the female body reinforced by the media is accompanied by the idea of sexual freedom, a way of approaching the woman to her body and sexuality, but which tends to be used as a reaffirmation of the female body as an object to be consumed.

Keywords: Violence against women. Reification. Capitalism. Social Work.

\section{Introdução}

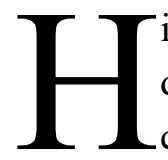

istoricamente as mulheres sofrem com a naturalização e perpetuação de uma imagem inferiorizada, assimétrica em relação ao homem, que goza dos privilégios próprios da sociedade patriarcal. Tais imagens referenciam uma concepção de pertencimento da mulher à antigas 
normas de que a ela cabe o cuidado da família e do lar. Essa divisão não é aleatória - com a instauração da propriedade privada e a necessidade de herdeiros, a mulher perde a sua autonomia e passa a existir em função da família: casar, gerar filhos e cuidar da casa, do marido e da prole, tornando-se uma extensão do homem (Wolf, 1992). Sua atuação dentro da sociedade capitalista e patriarcal é cuidadosamente delimitada, na intenção da perpetuação do status quo. Partindo dessa compreensão, corroboramos com a ideia de que

As condições em que vivem homens e mulheres não são produtos de um destino biológico, mas, antes de tudo, construções sociais. Homens e mulheres não são uma coleção — ou duas coleções — de indivíduos biologicamente distintos. Eles formam dois grupos sociais que estão engajados em uma relação social específica: as relações sociais de sexo. (Kergoat, 1996)

É com essa categoria de relações sociais de sexo que iremos trabalhar, entendendo que, como afirma Cisne (2014), ela representa "relações sociais mais amplas, permeadas pelos conflitos e antagonismos de classe". A autora declara que a utilização e compreensão de "relações sociais de sexo" em vez de "relações de gênero", nos permite ampliar o conceito em torno da desigualdade e opressão entre os sexos, raça e classe, visto que a categoria gênero muitas vezes "é destituída da noção de hierarquia presente na relação entre os sexos e das outras desigualdades estruturantes".

A análise apresentada aqui foi baseada no método materialista histórico dialético de Marx e em autoras como Saffioti (2004) e Cisne (2014), que relacionam as relações de exploração e opressão a que nós mulheres estamos submetidas à base material, à forma como a sociedade está dividida em classes e ao modo de produção vigente, visto que as ideias por si só e abstratamente não produzem a desigualdade.

Tendo esse norte, buscaremos analisar a violência contra as mulheres como uma das múltiplas expressões da questão social ${ }^{1}$ no capitalismo

1. Segundo Iamamoto (1998, p. 27) “A questão social é apreendida como um conjunto das expressões das desigualdades da sociedade capitalista madura, que tem uma raiz comum: a produção social é cada vez 
contemporâneo. Tal violência tem relação direta com as relações sociais de sexo e gênero. Para tanto, é mister compreender o movimento histórico de dominação e coisificação da mulher no capitalismo, reproduzidos principalmente pela mídia, e os seus rebatimentos na contemporaneidade, entendendo que as relações sociais de sexo estabelecidas contribuem diretamente para os altos índices de violência contra a mulher. A mídia ${ }^{2}$ é um instrumento privilegiado, mas não o único, de perpetuação e naturalização desse lugar da mulher.

O número alarmante de mulheres vítimas de violência se configura como uma expressão da questão social, consequência das relações sociais desiguais estabelecidas no modo de produção vigente, que traz consequências reais para a vida da classe trabalhadora, em especial às mulheres. A instauração de uma sociedade patriarcal foi (e continua sendo) muito útil para a manutenção desse modo de produção e tem como grave consequência a coisificação da mulher, reafirmando a ideia de que as mulheres são, de diversos modos, submetidas às vontades do patriarcado, feitas para satisfazer seus prazeres e "cuidar" de seus filhos, dificultando o desenvolvimento social, econômico, político, cultural etc. e contribuindo para o aumento dos diversos tipos de violência cometidos contra elas.

Nossas análises expressam a necessidade de construção de reflexões acerca dos diferentes tipos de violência que acometem as mulheres e que se transformam em demandas objetivas para os assistentes sociais cotidianamente. É preciso que esse profissional entenda as raízes materiais, econômicas, políticas e históricas dessas violências, mas que também compreenda que tais raízes se objetivam através de instituições, como família, Igreja, mídia etc. E são essas instituições que contribuem fortemente para a construção da subjetividade da mulher, a forma de se perceber na relação com o outro,

\footnotetext{
mais coletiva, o trabalho torna-se mais amplamente social, enquanto a apropriação dos seus frutos mantém-se privada, monopolizada por uma parte da sociedade".

2. A mídia não é a única, mas é um instrumento privilegiado para cumprir este papel, assim como a família (Cisne, 2014), a religião (Sousa, 2017), entre outros.
} 
com os agressores e com os profissionais, mas também consigo mesma. Conhecer como as mulheres constroem relações com o outro, mas também com o próprio corpo e com a sexualidade, é mister para que os assistentes sociais forjem respostas que contribuam para o fortalecimento subjetivo e objetivo das mulheres, possibilitando a construção conjunta de ferramentas para identificar e enfrentar situações de violência. Superar tais situações, entretanto, não pode ser feito sem políticas públicas, que garantam condições materiais para que as mulheres construam esse enfrentamento.

\section{A coisificação da mulher veiculada pela mídia}

A cobrança sobre o corpo perfeito é um importante fato para o aprisionamento objetivo e subjetivo das mulheres, uma das formas de repressão e opressão mais difíceis de identificação e libertação. A padronização da beleza, que acarreta uma série de problemas de proporções físicas e psicológicas, em que a mulher se vê na obrigação de estar enquadrada a determinado tipo de corpo, de cabelo, em que até mesmo algo inevitável e comum a todos como o envelhecer lhes é negado. Wolf (1992, p. 11) sinaliza que "quanto mais numerosos foram os obstáculos legais e materiais vencidos pelas mulheres, mais rígidas, pesadas e cruéis foram as imagens da beleza feminina a nós impostas". A ideia propagada de que a beleza está intrinsecamente ligada à felicidade contraditoriamente causa o sofrimento de muitas mulheres que farão de tudo para alcançar essa felicidade falsamente vendida.

A vigilância sobre o corpo e a cobrança pela imagem perfeita começam desde a infância, mas é a partir da adolescência que as imposições de padrão de beleza começam a pesar sobre as meninas, visto que tudo o que está em volta só representa um tipo de pessoa: a menina "ideal" é branca, magra, cabelos lisos, roupas do mesmo estilo e assim por diante, fazendo com que as meninas se sintam desconfortáveis diante de sua própria imagem e busquem meios para se "ajustar" ao que lhe é imposto. 
Dados $^{3}$ divulgados pela Sociedade Brasileira de Cirurgia Plástica em 2013 revelaram que o número de adolescentes com idade entre catorze e dezoito anos que recorrem a cirurgias plásticas por não se sentirem bem com o próprio corpo teve um aumento de $141 \%$ em quatro anos, quase 3,5 vezes maior que o número de adultos que buscaram tais procedimentos cirúrgicos no mesmo período. Os procedimentos mais procurados são os de mamoplastia de aumento, lipoaspiração, rinoplastia, entre outros procedimentos invasivos que, na maioria das vezes, não se faziam necessários além do bem-estar pessoal proposto pela alteração de algo natural no corpo (como os seios, por exemplo).

$\mathrm{Na}$ idade adulta, as mulheres continuam presas a essa teia de sofrimento, pois o modelo-padrão é inatingível para todas que não permanecem jovens, magras, com cabelo impecável e maquiagem perfeita como ousam nos apresentar. A consequência de tentar se manter dentro dos padrões é dolorida e, muitas vezes, prejudicial para a própria saúde da mulher, que se propõe a seguir dietas restritivas da moda, usar produtos que lhe causam males, dores, cirurgias plásticas etc.

A indústria da beleza, ao tratar a mulher como um objeto, lucra tanto com a insegurança introjetada nas mulheres desde muito jovens e que as acompanha ao longo da vida, quanto contribuindo ainda para "manter intacto o domínio masculino", visto que, ao incentivar a disputa entre o sexo feminino e o cuidado excessivo com a beleza, há, consequentemente, o enfraquecimento das lutas feministas. A imagem da mulher feminista passada é o inverso do padrão ideal. Sempre que há uma representação nesse sentido, vemos uma mulher com características tidas como masculinas, com pelos aparentes no corpo, roupas que não fazem jus à moça delicada e moderna que a imagem de mulher ideal apresenta (entre outras formas

3. Brasil lidera ranking de cirurgias plásticas no mundo. Disponível em: $<\mathrm{http}: / / \mathrm{www} 2$. cirurgiaplastica.org.br/de-acordo-com-a-isaps-brasil-lidera-ranking-de-cirurgias-plasticas-no-mundo/>. Acesso em: 15 maio 2017. Número de cirurgias plásticas entre adolescentes aumenta 141\% em 4 anos. Disponível em: <http://www2.cirurgiaplastica.org.br/numero-de-cirurgias-plasticas-entre-adolescentes-aumenta-141em-4-anos/>. Acesso: 15 maio 2017. 
estereotipadas e pejorativas) com a intenção clara de afastar a associação entre uma pessoa que deseja se enquadrar no padrão de beleza imposto com a feminista que luta por direitos iguais. A mulher aqui fica reduzida a um corpo, que deve ser visto e apreciado, mas que não deve se constituir como instrumento de luta.

Defendemos aqui que nascer homem ou mulher confere "lugares e papéis sociais", imagens, atributos diferentes que são construídos a partir do sexo genital. Esses papéis, entretanto, são construídos de formas assimétricas e muito bem sedimentados em nossa cultura, tendo a mídia ${ }^{4}$ papel importante nesse processo. "A mídia, grande reprodutora da ideologia dominante, contribui fortemente para a formação de nossa subjetividade" (Moreno, 2014) e suas diversas plataformas, tais como jornais, revistas, televisão, rádio e internet, estão cheias dessas caracterizações estereotipadas, onde a imagem da mulher ideal reproduzida é "a bela, recatada e do lar", 5 enquanto corrobora com a propagação do mito da beleza, da imagem da mulher objeto, subalternizada, inferiorizada, coisificada etc.

Para Marx (2003, p. 219), no modo de produção capitalista, "o processo de trabalho é um processo que ocorre entre coisas que o capitalista comprou, entre coisas que lhe pertencem". Tal afirmação já indica que nesse modo de produção a classe trabalhadora, homens e mulheres, são meras mercadorias no processo de produção. Em outro texto, Marx afirma que "na relação do trabalho estranhado cada homem considera, portanto, o outro segundo o critério e a relação na qual ele mesmo se encontra como trabalhador" (Marx, 2004, p. 86). Se o trabalhador é reduzido à condição de mercadoria, ele considera o outro segundo essa mesma condição: mercadoria. Aí pode estar a raiz da coisificação, que é resultado e produto da sociabilidade burguesa.

4. Com todo suporte de difusão da informação que constitui um meio intermediário de expressão capaz de transmitir mensagens; o conjunto dos meios de comunicação social de massas. Abrangem esses meios o rádio, o cinema, a televisão, a imprensa, os satélites de comunicações, os meios eletrônicos e telemáticos de comunicação etc.

5. Matéria da revista Veja que apresentava a mulher do então presidente Temer como uma mulher jovem, que gosta de vestidos abaixo do joelho e dedicada à família e ao lar. Disponível em: $<$ https://www.google. com.br/amp/veja.abril.com.br/brasil/marcela-temer-bela-recatada-e-do-lar/amp/>. Acesso em: 13 jun. 2017. 
Mas se a alienação do produto do trabalho e consequente mercantilização do homem (enquanto gênero humano) é comum para homens e mulheres, coloca-se como desafio compreender que lugar tem a mulher na construção de papéis sociais de sexo para ser reduzida à condição de coisa de forma tão radical. A mulher sofre alienação enquanto mulher e não apenas enquanto trabalhadora - e isso tem raízes e consequências ainda mais profundas para percepção e desconstrução deste lugar. É Engels (2010) quem nos dá pistas para essa compreensão, ao resgatar o papel que o homem vai assumindo na sociedade com a criação do excedente. É a necessidade de manter o excedente que traz possibilidades para a criação da família patriarcal, como a conhecemos hoje, e é essa forma de organização que dá ao homem o poder sobre os membros da família - mulheres e crianças. A mulher passa assim a ser propriedade do homem, destinada à procriação, a cuidar da casa e dos filhos, bem como dar prazer sexual ao homem - reprodução da força de trabalho a ser explorada. É o desenvolvimento da noção de família, de monogamia (feminina), de heterossexualidade compulsória, que vai paulatinamente construir a "supremacia absoluta do homem sobre o sexo feminino" (Engels, 2010, p. 89).

Daí se constroem, a partir de uma base econômica, diversos mecanismo de ordem cultural e política, ancorados muitas vezes em argumentos biológicos, moralistas e religiosos, de manutenção da desigualdade de classe, que agudizam a condição da mulher enquanto propriedade e objeto. É nessa esteira que o sexo se constitui como uma forma de prazer para o homem, e o corpo da mulher uma mercadoria ou um objeto que pode ser utilizado para esse prazer.

Não é incomum passar pela rua e notar olhares que perseguem, ouvir assobios e cantadas, na maioria das vezes depreciativas, até abordagens mais agressivas, nas quais a resposta negativa da mulher às investidas masculinas não é levada em consideração. Lourenço (2014, p. 5), utiliza o termo objetificação, que "consiste em analisar alguém no nível de um objeto, sem considerar seus atributos emocionais e psicológicos". A autora exemplifica dizendo que "podemos ver a objetificação da mulher em 
propagandas que só focam no atributo sexual ou físico, sem outro tipo de apelo emocional". Produtos voltados para o sexo masculino que relacionam a aquisição de determinado bem com a conquista automática de uma ou várias mulheres são exemplos claros de como a mídia caracteriza a mulher como um objeto de fácil aquisição, pois segundo os conteúdos publicitários, basta uma aplicação de um desodorante para as mulheres "avançarem" sobre os homens. A submissão é a premissa, e a violência para "adquirir" esse produto é naturalizada e até estimulada. A reprodução de estereótipos que ocorre na mídia desde anúncios publicitários, matérias tendenciosas, novelas, até programas de auditório, entre outros, contribui para a formação do imaginário masculino que não corresponde à realidade das mulheres, mas reflete como a sociedade patriarcal enxerga e atribui papéis às mulheres.

Façamos o exercício de pensar nas propagandas que são transmitidas na TV e em como a mulher é representada. Iremos perceber que em sua maioria são mulheres brancas, jovens, magras que aparecem hipersensualizadas ou, em contrapartida, mulheres fazendo trabalhos domésticos. Vamos fazer um exercício de reflexão sobre alguns anúncios publicitários que ilustram esta realidade.

A cervejaria veiculou uma peça publicitária ${ }^{6}$ com duas imagens: de um lado, uma mulher de salto alto, saia e camiseta bebendo água em um bebedouro comum. Ao lado, uma imagem da mesma mulher diante de um bebedouro bem mais baixo, onde ela tem que se curvar de forma que sua saia fique levantada. A imagem traz escrito que se o inventor do bebedouro consumisse a marca $X$ de cerveja, ele não seria como o que temos hoje, alto e confortável, mas baixo, de forma que, ao se abaixar para acessá-lo, a mulher ficasse exposta aos olhares dos homens. A imagem, além de coisificar a mulher e a colocar em posição de subserviência ao homem, ainda direciona a campanha totalmente para o público masculino, como se os homens fossem

6. Disponível em: <https://quasepublicitarios.wordpress.com/2010/06/23/anuncios-da-skol/>. Acesso em: 20 abr. 2017. 
os únicos consumidores de cerveja, reforçando também o preconceito contra mulher que gosta de beber.

Outro anunciante, uma marca de desodorante ${ }^{7}$ que veicula o slogan "Misture-os e acumule mulheres", associa a utilização de duas fragrâncias do produto com a conquista não de uma, mas várias mulheres. A imagem traz um homem deitado no chão e mais de vinte mulheres vestindo apenas calcinha e sutiã deitadas/expostas ao redor dele. Há um padrão representado na imagem: todas são jovens, magras e brancas. A ideia de colecionar mulheres, ter todas ao alcance do homem, está presente na imagem e reflete como essa ideia é comum e aceitável para os homens, enquanto para as mulheres o relacionamento com vários homens não é tolerado.

Um anúncio de ternos masculinos ${ }^{8}$ reproduz claramente uma cena de dominação e violência contra a mulher: um homem branco, rico e bem vestido com uma mulher seminua sobre o seu carro numa imagem que indica um enforcamento da mulher com uma gravata. $\mathrm{O}$ corpo da mulher está inerte sobre o capô do carro e ela está sendo puxada pelo pescoço pela gravata do homem que olha para a câmera/leitor da peça publicitária. É chocante quando pensamos que a associação da imagem de poder do homem está diretamente ligada à imagem de submissão e violência contra a mulher e como isso é facilmente reproduzido em uma propaganda que visa a venda de um produto para o público masculino, que acredita que com essa campanha obterá sucesso nas vendas, pois "que homem não gostaria de sentir-se poderoso tendo uma mulher sob seu domínio?”.

Uma grife de moda unissex ${ }^{9}$ é ainda mais cruel ao retratar a cena de dominação de uma mulher por vários homens, fazendo alusão a um estupro. Um homem sem camisa segura os punhos da mulher deitada, enquanto outros

7. Disponível em: <http://consumoepropaganda.ig.com.br/index.php/2012/09/19/axe-tera-de-mudar-anuncio/>. Acesso em: 20 abr. 2017.

8. Disponível em: $<$ http://exame.abril.com.br/marketing/13-anuncios-acusados-de-promover-a-violencia-contra-a-mulher/>. Acesso em: 20 abr. 2017.

9. Disponível em: $<$ http://exame.abril.com.br/marketing/13-anuncios-acusados-de-promover-a-violencia-contra-a-mulher/>. Acesso em: 20 abr. 2017. 
três (um sem camisa, outro com a camisa entreaberta) observam a cena de dominação e a encaram com olhar intimidante. A campanha foi duramente criticada, contudo é facilmente encontrada em uma rápida busca pela internet.

Essas campanhas têm em comum um profundo desrespeito à mulher, pois todos os atributos considerados como tipicamente femininos são depreciados e carregados de preconceito. A associação da venda de determinado produto destinado ao público masculino com o poder de conquista ou dominação sobre as mulheres é comum, e poderíamos citar aqui muitos outros exemplos, bem como poderíamos listar todas as campanhas que associam produtos de limpeza para casa à imagem de mulheres lindas e felizes com seus afazeres domésticos, como se a limpeza da casa fosse responsabilidade exclusiva das mulheres - e como se toda mulher se sentisse linda e feliz ao fazer uma faxina em casa.

$\mathrm{O}$ exercício que fizemos acima tem o mesmo resultado quando paramos para analisar as novelas transmitidas: os papéis reservados à mulher geralmente a mostram em posição de inferioridade em relação ao homem, competindo com outra mulher pelo mesmo homem, supervaidosas, falsas, interesseiras etc. Às mulheres negras são reservados papéis de segundo escalão, nos quais ficam evidentes principalmente seus atributos físicos ou estão interpretando a empregada doméstica do folhetim. Enquanto os personagens masculinos que desempenham um papel de vilão são aceitos como um simples cafajeste, as mulheres são as megeras, odiadas, que merecem sempre um final trágico e/ou humilhante. Programas de auditório utilizam literalmente as mulheres como enfeite, um "bibelô de biquíni", dançando para atrair o público que vez ou outra ainda ganha de "brinde" um zoom estrategicamente posicionado no corpo da mulher.

Estudos ${ }^{10}$ afirmam que os brasileiros passam mais de cinco horas por dia em frente à TV e mais de nove horas na internet, ou seja, metade do dia consumindo produtos distribuídos pela mídia, que possui grande poder de

10. Estudo revela que brasileiro passa mais de nove horas por dia na internet. Disponível em: $<$ http:// exame.abril.com.br/tecnologia/brasileiro-consome-20-horas-semanais-de-tv/ $><\mathrm{http}: / /$ noticias.r7.com/ 
influência e promoção de ideias ao atingir todas as classes sociais e reproduzir de forma massiva determinado conteúdo. Por isso, analisar criticamente como a mulher vem sendo retratada nas diversas plataformas de mídia é importante para entendermos como isso vem refletindo na realidade. E a realidade tem sido muito cruel para as mulheres, tanto objetivamente, com a violência, os abusos, os estupros; como subjetivamente, quando elas se veem presas às teias de opressão e repressão próprias da sociedade patriarcal, como o controle sobre seu corpo, sobre a sua sexualidade.

A sexualidade feminina é superexplorada e garante bilhões à indústria do entretenimento, que abusa da imagem da mulher enquanto símbolo sexual. Em uma produção cinematográfica de heróis, por exemplo, os homens são retratados de forma que a característica do seu personagem prevaleça, geralmente se mostrando fortes, viris e sempre acompanhados por uma "mocinha" frágil e indefesa, que necessita de sua proteção. As mulheres nessas produções contam com roupas curtas, justas, visivelmente desconfortáveis, expondo de forma gratuita o seu corpo e que não tem nenhuma outra razão além de mexer com o imaginário masculino.

Recentemente, tornou-se viral na rede social ${ }^{11}$ Facebook um post pela busca da palavra "lésbica" - a palavra é associada a pornografia, com a aparição de diversos sites de vídeos pornográficos. Não há uma definição da palavra em seu sentido literal para quem faz a busca procurando por orientação e conhecimento. Quando a busca é pela palavra "gay", a primeira página do Google exibe a definição da palavra, reportagens de sites sobre o assunto, imagens de casais, entre outras informações que não possuem uma conotação pornográfica (embora também nos leve a páginas de pornografia, mas em número muito menor e menos agressivo do que ocorre com a palavra lésbica).

\footnotetext{
tecnologia-e-ciencia/estudo-revela-que-brasileiro-passa-mais-de-nove-horas-por-dia-na-internet-23012015>. Acesso em: 20 abr. 2017.

11. "Enteadas" e "lésbicas": a relação entre pornografia e violência e por que achamos isso normal. Disponível em: <https://medium.com/@thamiresmotta/enteadas-e-1\%C3\%A9sbicas-a-rela\%C3\%A7\%C3\%A3o-entre-pornografia-e-viol\%C3\%AAncia-e-por-que-achamos-isso-normal-de85ecfd3828> Acesso em: 20 maio 2017.
} 
Isso nos faz pensar sobre como tudo o que está relacionado às mulheres é coisificado, fetichizado, apropriado e superexplorado.

A indústria pornográfica leva ao extremo a ideia de coisificação ao explorar o sexo de forma desumana, em que a mulher fica à mercê de todo tipo de violência e humilhações e, muitas vezes, com um sorriso no rosto. Com o avanço tecnológico e o aquecimento econômico ocorrido nos últimos anos, o mundo digital ficou mais acessível (D’Abreu, 2013). Se antes, para consumir pornografia, era preciso ter dinheiro, se deslocar até uma locadora de vídeos ou banca de jornal, hoje há uma infinidade de conteúdos que estão catalogados ao acesso livre de todos, em sites que categorizam o sexo de acordo com os fetiches de seus expectadores - fetiches estes que exigem cenas cada vez mais violentas para as mulheres. Segundo Anfra (2009, p. 3),

Desaparecem progressivamente os atores homens, restando apenas seus genitais, o que só não acontece com a atriz, e isto porque a face dela é importante para outro ato de transgressão recorrente, a ejaculação em sua face, como se no enredo do filme se efetuasse um ataque ou uma vingança da força contra a beleza.

O autor questiona que tipo de sexo é esse que está sendo representado pela indústria pornográfica, visto que esta mudou muito desde o seu surgimento, que seguia uma linha mais erótica, com enredo carregado de humor e sexo mais próximo do natural. O que vemos hoje é uma radicalização do ato sexual, em que se prioriza o fetiche e o bizarro. Verdadeiras cenas de estupro são reproduzidas com tamanha naturalidade, utilizando de atrizes que, de tão jovens, induzem o expectador a acreditar que se trata de uma adolescente, as chamadas "novinhas".

Uma pesquisa realizada pelo The Economist ${ }^{12}$ lista a procura por sites de vídeos gratuitos em diversos países. No gráfico a seguir podemos perceber

12. NakedCapitalism. Disponível em: $<$ http://www.economist.com/news/international/21666114-internet-blew-porn-industrys-business-model-apart-its-response-holdslessons? $\mathrm{fsrc}=\mathrm{scn} / \mathrm{tw} / \mathrm{te} / \mathrm{pe} / \mathrm{ed} /$ nakedcapitalism>. Acesso em: 20 maio 2017. 
que a maior parte das buscas é para vídeos que representem mulheres lésbicas e jovens. PornHub, o maior canal de Mindgeek, ${ }^{13}$ afirma ter tido quase 80 bilhões de visualizações de vídeo no ano de 2014 e mais de 18 bilhões de visitas (ver gráfico).

Gráfico 1:The porn supremacy ${ }^{14}$ (PornHub traffic, 2014, \% do total)

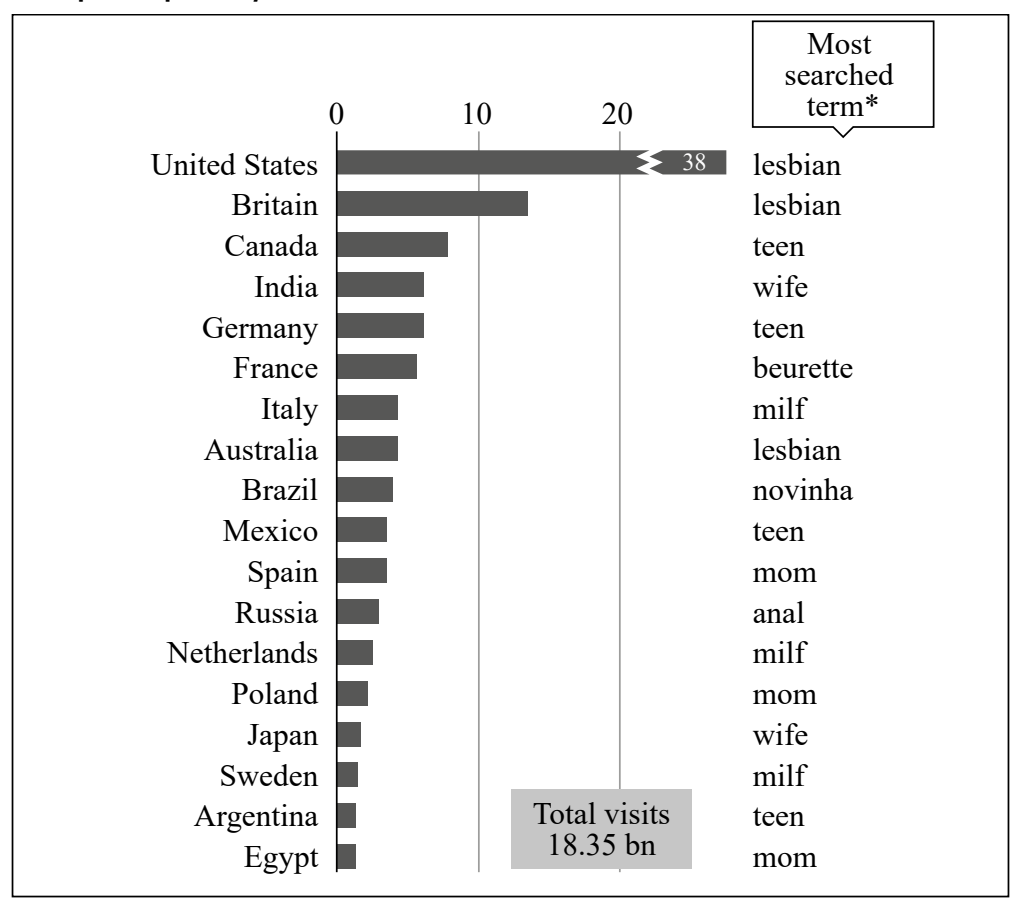

Source: PornHub

* Excluding nationality-related terms

Fonte: The Economist, 2015.

Nos dezoito países listados, a maioria das buscas por vídeos é de mulheres, em oito deles a maior parte das buscas é por adolescentes ou lésbicas.

13. Mindgeek é uma empresa global de TI que atua no fornecimento de conteúdo, streaming de mídia e publicidade on-line. Suas operações estão relacionadas principalmente à pornografia na internet, mas também incluem outras propriedades on-line. É dona dos maiores sites e estúdios de pornografia do mercado atual.

14. A supremacia pornô (tradução livre). 
É esse o tipo de sexo que está sendo consumido, é esse o tipo de sexo que aparece quando se faz uma busca por um site de pornografia na internet ou simplesmente quando procuramos por uma palavra solta, como nos casos supracitados. A sexualidade da mulher é completamente ignorada por essa indústria que produz conteúdos voltados apenas para o público masculino, negando à mulher a possibilidade de desejar, de ter fantasias, de sentir prazer e de viver livremente sua sexualidade.

$\mathrm{Na}$ contracorrente está a produtora e diretora Erika Lust,${ }^{15}$ que tem uma proposta de pornografia mais real, não mecânica, com atores e atrizes que representam a realidade e a diversidade, mas que tem acesso restrito aos assinantes do seu site - o conteúdo deste, ao contrário dos mais "populares", não é facilmente encontrado, pirateado ou reproduzido como os demais.

Além das consequências de agressão e violência reais a que as atrizes da indústria pornográfica estão sujeitas, outro problema do consumo desenfreado desse tipo de material é como isso se reflete na realidade: aceitação e naturalização da violência. É aí que está a grande questão que envolve esse tipo de pornografia - ela promove a desigualdade entre a vivência do prazer entre homens e mulheres, a submissão e incentiva a agressão sexual contra mulheres (D’Abreu, 2013). Segundo a autora, a exposição a mídias pornográficas com conteúdo violento tem "relação com atos de coerção sexual por contribuir para a banalização das relações interpessoais". No caso dessas produções, a mulher é usada para a satisfação sexual do homem, e o ponto alto dos conteúdos é a ejaculação masculina. A violência nas cenas nunca é realmente rejeitada pela mulher, que até resiste no início, mas no final ainda demonstra ter sentido prazer com o ato violento, causando excitação no expectador e a falsa impressão de que toda mulher submetida à coerção ainda sentirá prazer.

A violência explícita contra a mulher está presente não só na indústria pornográfica, mas em diversas produções televisivas e cinematográficas

15. Erika Lust é diretora de cinema adulto independente, roteirista e produtora. Foi pioneira da chamada pornografia feminista e é autora de vários livros, entre eles a novela erótica Nora’s Songe (2013). 
livremente distribuídas e que possuem a única intenção de entreter o expectador com cenas de humilhações, abusos, estupros.

A indústria do entretenimento, como qualquer outra no modo de produção capitalista, está interessada em vender seus produtos e obter lucro com os mesmos. Logo, ela se adapta ao mercado, não importando as consequências sociais de suas produções. Não estamos dizendo aqui que os vídeos pornográficos são responsáveis pelos casos de estupro, visto que estes já acontecem muito antes desta indústria, tampouco acompanhar uma novela ou um seriado por si só servem como incentivo para a violência cometida contra as mulheres. Porém, não há como negar que as relações sociais que estão sendo construídas são diretamente influenciadas pelo que está sendo representado pela mídia que naturaliza e banaliza a violência e, como supracitado, contribuem para a formação da nossa subjetividade.

\section{Conclusão}

A violência contra a mulher deve ser combatida em todas as suas formas. Há um movimento de luta contra as representações machistas das mulheres na mídia, e hoje já podemos observar uma tentativa de mudança em alguns segmentos midiáticos. Contudo, segundo Moreno (2014), "qualquer tentativa de adequação de seu foco, de democratização de seu conteúdo, termina esbarrando em sua caracterização, por "eles", de censura ou de cerceamento à liberdade de comunicação... comercial”. Essa mudança não é gratuita. Ela acompanha as tendências de intolerância e até o boicote a produtos e marcas que exploram a mulher de forma estereotipada e preconceituosa. Com o advento das mídias sociais, rapidamente esses produtos midiáticos são problematizados, alcançando um grande número de pessoas, fazendo até com que alguns deles sejam retirados de circulação. E como forma de alcançar o público feminino, vêm trazendo à tona temas importantes para a discussão de enfrentamento ao machismo, reflexão sobre padrão de beleza, diversidade sexual etc. Consideramos que suscitar tais reflexões é importantíssimo, mas ainda ocorrem como uma forma de influenciar o 
consumo. Logo, ainda são insuficientes na luta mais ampla de combate à opressão das mulheres.

Em contrapartida, a liberdade sexual é uma das pautas mais debatidas e influenciadas pela mídia. Falar em liberdade sexual em uma sociedade marcada pela repressão do prazer da mulher, pelo moralismo e conservadorismo é quase revolucionário, mas corre-se o risco de continuar a apresentar a mulher como um objeto. É importante destacar que ainda que consiga se libertar de muitos padrões e viver a sexualidade de forma mais livre, a mulher ainda será julgada e dela ainda será esperado um comportamento de uma "santa", uma "dama", diante de uma sociedade que não aceita a sua liberdade. É uma mudança importante, de pertencimento do corpo e do prazer da mulher para ela mesma. Mas é questionável que uma das bandeiras de luta dos movimentos feministas mais divulgada e incorporada pela mídia e a sociedade em geral seja justamente aquela que favorece diretamente os homens.

A contradição apresentada entre a mulher "sexy da mídia" e a "santa", "da igreja", "bela, recatada e do lar", traz conflito e sofrimento para as mulheres de forma geral. Pois tanto as que acreditam e lutam por uma liberdade sexual plena sofrem com os julgamentos da sociedade patriarcal, revelando que essa mudança não vem acompanhada de outras importantes e que pode estar sendo tão incentivada porque, ao mesmo tempo que demonstra maior poder da mulher sobre seu corpo e seu prazer, também coloca o corpo da mulher mais disponível para os homens. Entre as consequências desses enquadramentos, o adoecimento físico e mental e a sujeição aos diversos tipos de violência e abusos fazem parte da realidade das mulheres na contemporaneidade.

As mudanças são insuficientes (embora muito importantes), visto que ainda há um movimento conservador latente que insiste em estabelecer um lugar de inferioridade e subalternidade para a mulher, ora reprimindo, ora coisificando e sexualizando nossos corpos - como se só nos coubesse esses dois papéis, "santa" ou "pecadora", invisibilizando nosso desejo. Ao mesmo tempo, esse movimento concede ao homem poder, que acaba muitas vezes 
se configurando como destrutivo, como nos crescentes casos de violência e abusos cometidos contra as mulheres.

Sabemos que essa subserviência da mulher em relação ao homem é construída historicamente, e desbravar esse processo é imperativo para superá-lo, buscando elementos que nos ajudem a entender a realidade atual de abuso e violência contra a mulher, fazendo uma relação com a escassez de políticas públicas que visam assegurar maior proteção, bem como as formas de resistência dos movimentos de mulheres, que vêm lutando arduamente para a conquista de direitos, mas que ainda encontram muita dificuldade e reconhecimento mesmo entre as mulheres.

Entendemos, entretanto, que ter conhecimento das relações de exploração e opressão não é suficiente para que os homens abram mão dos privilégios reproduzidos historicamente. É preciso um limite. Romper com relações e preconceitos tão arraigados é impossível individualmente, pois mesmo que homens e mulheres questionem esses papéis e lugares sociais, há toda uma estrutura material reafirmando esse lugar. Logo, a mídia reforça, reafirma, naturaliza, porém a base da opressão não é apenas cultural, mas compreende dimensões econômicas, políticas, sociais e legais.

Os assistentes sociais têm nessa conjuntura um grande desafio de compreender e identificar as diferentes opressões que acometem as mulheres. A formação em Serviço Social tem uma tarefa importantíssima de capacitar os assistentes sociais para esse enfrentamento, suscitando nos alunos uma consciência de classe antirracista, antipatriarcal e anti-heterossexista, assim como vinculada às lutas dos movimentos sociais (negras/os, indígena, feminista, LGBT e outros) (Abepss, 2016). Essas temáticas devem então estar presentes em toda a formação profissional, conforme preconiza a Associação Brasileira de Estudos e Pesquisa em Serviço Social (Abepss), que, em dezembro de 2014, na Assembleia realizada durante o XIV Enpess em Natal $(\mathrm{RN})$, aprovou, por unanimidade:

- A inclusão, nos conteúdos curriculares obrigatórios, do debate sobre as relações sociais de classe, sexo/gênero, etnia/raça, sexualidade e geração de forma correlacional e transversal. 
- A realização de, no mínimo, uma disciplina que tematize o Serviço Social e as relações de exploração/opressão de sexo/gênero, raça/etnia, geração e sexualidades, preferencialmente, antes da inserção da(o) estudante no campo de estágio. Aqui, ressaltamos, ainda, as Leis ns. 10.639/03 e 11.645/2008, assim como a Resolução n. 1 do Conselho Nacional de Educação - CNE/ MEC, no que diz respeito à incorporação obrigatória do tema sobre relações étnico-raciais nos currículos.

- O estímulo à realização de debates, eventos, oficinas e seminários temáticos sobre as relações de exploração/opressão de sexo/gênero, raça/etnia, geração e sexualidades.

- Apoio aos movimentos sociais e espaços de lutas anticapitalistas, antirracista, antipatriarcal e anti-heterossexista, por meio de parcerias, projetos de extensão, pesquisa, entre outros.

- A promoção de espaços de estudos e pesquisas sobre o sistema capitalista-patriarcal-racista-heterossexista e adultocêntrico. (Abepss, 2016)

É urgente que as unidades formadoras de assistentes sociais incorporem esses componentes curriculares, uma vez que a questão social é mediatizada por tais relações e somente o acúmulo teórico e crítico possibilita descortiná-las e identificá-las.

Enquanto assistentes sociais, precisamos não só conhecer essa forma de opressão à luz da teoria social crítica, mas identificar, conhecer, fortalecer e engrossar os movimentos organizados de mulheres, buscando trabalhar coletivamente no enfrentamento dessa expressão da questão social, na luta pela superação do sistema capitalista-patriarcal e pela construção de uma sociedade justa e igualitária para todos, como prevê um dos princípios fundamentais expresso no código de ética do Serviço Social: "Opção por um projeto profissional vinculado ao processo de construção de uma nova ordem societária, sem dominação, exploração de classe, etnia e gênero". ${ }^{16}$

Cabe aqui ressaltar que mesmo com a construção de um novo projeto societário é preciso ter movimentos de mulheres fazendo frente ao

16. Código de ética do/a assistente social. Lei n. 8.662/93 de regulamentação da profissão. 10. ed. rev. e atual. Brasília: Conselho Federal de Serviço Social 2012. 
conservadorismo presente também entre os que lutam pela superação de modo de produção, pois de acordo com Cisne, "o processo de organização do movimento de mulheres deve promover uma luta não apenas contrária ao sistema, mas, também, ao conservadorismo presente nas organizações de esquerda, o que, para nós, é indispensável para a consolidação de um movimento, de fato, revolucionário" (2014, p. 92). Para tal, apontamos a necessidade de intensificar estudos e pesquisas que aprofundem a análise de categorias, como coisificação, alienação e ideologia.

A resistência e a construção coletiva de uma outra sociabilidade são a única opção. Do contrário, nos restarão velhos papéis socialmente impostos com novas roupagens, mas que não superam as cotidianas manifestações de violência, repressão e opressão.

Recebido em 17/1/18 - Aprovado em 23/2/18

\section{Referências bibliográficas}

ABEPSS. Notícias: GTP: Serviço Social, relações de exploração/opressão de gênero, raça/etnia, geração, sexualidades. 10 maio 2016. Disponível em: <http://www.abepss. org.br/noticias/apresentacao-graduacao-15>. Acesso em: 12 nov. 2017.

ANFRA, Douglas. A insustentável engenharia do desejo. 2009. Disponível em: $<$ http:// passapalavra.info/2009/08/10648>. Acesso em: 14 maio 2017.

CISNE, Mirla. Feminismo e consciência de classe no Brasil. São Paulo: Cortez, 2014.

CFESS. Código de ética do/a assistente social. Lei n. 8.662/93 de regulamentação da profissão. 10. ed. rev. e atual. Brasília: Conselho Federal de Serviço Social, 2012.

D'ABREU, Lylla C. F. Pornografia, desigualdade de gênero e agressão sexual contra mulheres. Revista Psicologia \& Sociedade, Belo Horizonte, n. 25, p. 592-601, 2013.

ENGELS, F. A família. In: . A origem da família, da propriedade privada e do Estado. Trad. Leandro Konder. 2. ed. São Paulo: Expressão Popular, 2010. p. 45-108. 
IAMAMOTO, Marilda Vilela. O serviço social na contemporaneidade: trabalho e formação profissional. São Paulo: Cortez, 1998.

KERGOAT, Danièle. Relações sociais de sexo e divisão sexual do trabalho. In: MARQUES LOPES, Marta Julia; MEYER, Dagmar Estermann; WALDOW, Vera Regina (Orgs.). Gênero e saúde. Porto Alegre: Artes Médicas, 1996.

LOURENÇO, Ana C. S.; ARTEMENKO, N. P.; BRAGAGLIA, A. P. A “objetificação" feminina na publicidade: uma discussão sob a ótica dos estereótipos. Intercom Sociedade Brasileira de Estudos Interdisciplinares da Comunicação XIX Congresso de Ciências da Comunicação na Região Sudeste — Vila Velha(ES) — 22 a 24 maio 2014.

LUST, Erika. Nora’s song. Espasa Libros, 2013.

MARX, Karl. Processo de trabalho e processo de produzir mais-valia. In:

O capital: crítica da economia política. Rio de Janeiro: Civilização Brasileira, 2003. . Trabalho estranhado e propriedade privada. In: .Manuscritos econômicofilosóficos de 1844. São Paulo: Boitempo Editorial, 2004.

MORENO, Raquel. As lutas feministas e a mídia. 2014. Disponível em: $<$ http://www. clam.org.br/artigos-resenhas/conteudo.asp?cod=11552>. Acesso em: 6 maio 2017.

SAFFIOTI, Heleieth Iara Bongiovani. Gênero, patriarcado, violência. São Paulo: Fundação Perseu Abramo, 2004.

SOUSA, Marília de Oliveira de. A resistência das mulheres no município de Rio das Ostras contra as formas de opressão, objetificação e violência. Rio das Ostras, 2017.

WOLF, Naomi. O mito da beleza: como as imagens de beleza são usadas contra as mulheres. Trad. Waldéa Barcellos. Rio de Janeiro: Rocco, 1992. 